\title{
ACGME Work Hours Regulations A Perspective from Neurology Program Directors
}

\author{
Brett Kissela, MD; and Wendy Peltier, MD
}

\section{Background}

$\mathbf{R}$ esident duty hour regulations developed by the ACGME went into effect in July 2003 and were preceded by much debate among medical educators. The regulations have forced change in the structure of many residency programs. All programs, regardless of specialty, have been forced to re-evaluate the structure of patient care systems in the academic setting where the resident role in service has been pivotal. Along with creating new service models, which hopefully will benefit both residents and patients, program directors are also faced with a new layer of administrative burden in providing documentation of compliance with the regulations in order to avoid citation by the ACGME and bad publicity. We write as new (Dr. Kissela) and more seasoned (Dr. Peltier) neurology program directors and consider the challenges of the duty hour regulations.

\section{Perspectives}

Kissela: There is a need for work hour regulations in training programs because there is convincing scientific evidence that cognitive performance declines with sleep deprivation. Although no one has proven that reducing resident work hours actually translates into improved patient safety, the value of the regulations will not be debated here. Rather, we will discuss the universal frustrations in trying to enact and enforce them.

Well-rested residents should provide better patient care. Each resident's ability to learn and their overall quality of life should improve with more reasonable working conditions. As a physician trained prior to duty hours regulation, I might have been happier as a resident, and would certainly have been a better husband and father, would similar regulations have been in place during my training.

Peltier: My memories of internship and residency include working 100 days without a day off. I recall practically living in the hospital and could locate my own films in the radiology file room at $3 \mathrm{am}$. I was also on a first name basis with most of the housekeeping staff. For me, internship was a rite of passage and the hard work and fatigue was a sign of success rather than defeat. We were expected by our staff to know every detail of a patient's history, testing, and travel though the complex system of an inner city hospital, and felt personally responsible for their care, safety, and wellbeing. We would never leave postcall until each "to do" list was complete, and it was considered foul play to "sign out" major care needs of a patient to a colleague. Duty hour regulations certainly would have changed my experience. I may have been more rested, but may not have developed my present day compulsions of follow-through on complex patient problems and commitment to continuity of care.

As neurologists, we are somewhat immune to the practical reality of duty hours compared to our colleagues in many academic centers, particularly in surgery programs. The most problematic component of the duty hours for most neurology programs has been the conflict created by the $24+6$ hour rule and maintaining resident continuity clinics, as these have often been scheduled in afternoon blocks. The long wait lists for patient access make erratic canceling of post-call resident clinics quite problematic in most programs. The additional struggles we will illustrate involve the lack of individual flexibility in a "one size fits all" policy.

For example, our biggest dilemma with the new rules is that they conflict with the unwritten rules and traditions followed by most residents and hinted at by Dr. Peltier above. These rules include:

1) Working more means that you are a stronger resident;

2) Don't leave work for others that you should have done yourself;

3) See one, do one, teach one;

4) Learn more by doing than listening or observing; and most importantly

5) Care for the patient above all else. 
Each day residents must face conflict between these unwritten rules and the duty hours regulations. Residency is learning by example and residents will mimic attendings who provide the best patient care. Attending physicians do not abide by duty hour limitations. They provide clinical care until the work is done without leaving work for colleagues. As the primary goal of residency training is learning patient care, the resident is driven to complete patient care activities. The duty hours regulations have created a need for new constructs that provide safe and reliable mechanisms for sign-out duties, crosscoverage, and continuity.

Residents handle stress differently, and this affects their work performance. Signing work out to colleagues will be necessary with the new regulations, and the amount of work signed out may vary considerably among residents. This may become a source of resident conflict. If a resident is physically or medically disabled, this may become a significant issue. For example, depression is more common than program directors likely admit. Supporting residents with such issues may require additional schedule changes and accommodations that are particularly difficult in small programs where extra staffing is difficult. A resident with depression may need to sign more work over to colleagues, who may misinterpret the sign-out as a sign of laziness or weakness, especially if they are not aware of the situation.

The duty hours regulations can also be counterproductive to the mission of graduate medical education. Residents may be conflicted between finishing patient care and formal education activities. Often, it is the educational conferences that are sacrificed. In theory, reduced hours would be counteracted by more time out of the hospital that could be used for residents to read and study. However, the ACGME has determined that the new regulations do not necessarily lead to more hours sleeping by most residents (personal communication, Ingrid Phillibert, ACGME Program Director's Course, April 2003). If residents do not spend extra time catching up on sleep, it seems unlikely that studying time is increased.

These are just some of the problems of this unfunded mandate. Monitoring of duty hours compliance is not a small issue for most programs. Some programs have thought of tracking resident's hours through a card system or electronically through the parking garage access but neither option is feasible or reliable. We can gain some insight from fellow directors in New York, but universal and reliable systems that residents will actually comply with are still forthcoming.

\section{Summary}

Duty regulations for residents are a good idea, and are not op- tional. Failure to document compliance in your program jeopardizes the graduate medical education system at your institution, as demonstrated by the ACGME's recent censure of the Internal Medicine program at Johns Hopkins. There can be serious repercussions if these rules are ignored. However, there are significant barriers to implementation that involve real cost to training programs. Given these challenges, we will depend on the professionalism of our residents to ensure compliance. We will also depend on our institutions to provide support and guidance, as program directors do not have time or desire to become duty hour police.

It is our expectation that residents will successfully make this paradigm shift, and amend their unwritten rules as follows:

1) I will work more efficiently and learn more if I am well-rested;

2) Knowing how to provide reliable and efficient sign-outs is an essential part of my training;

3) Learning to provide safe and efficient patient care despite limitations in the health care system is the goal, and will not be superceded by duty hours regulations; and

4) $100 \%$ compliance with these rules is necessary to maintain the quality of our training program for the future. 


\section{Neurology}

ACGME Work Hours Regulations: A Perspective from Neurology Program Directors Brett Kissela and Wendy Peltier

Neurology 2004;62;E3-E4

DOI 10.1212/WNL.62.1.E3

This information is current as of January 12, 2004

Updated Information \& Services

Permissions \& Licensing

Reprints including high resolution figures, can be found at: http://n.neurology.org/content/62/1/E3.full

Information about reproducing this article in parts (figures,tables) or in its entirety can be found online at:

http://www.neurology.org/about/about_the_journal\#permissions

Information about ordering reprints can be found online:

http://n.neurology.org/subscribers/advertise

Neurology ${ }^{\circledR}$ is the official journal of the American Academy of Neurology. Published continuously since 1951, it is now a weekly with 48 issues per year. Copyright . All rights reserved. Print ISSN: 0028-3878. Online ISSN: 1526-632X.

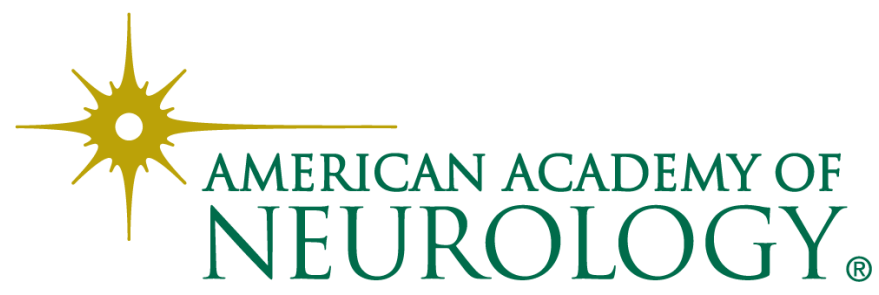

